\title{
Intramuscular myxoma of the hypothenar muscles
}

\author{
Freih Odeh Abu Hassan · Maha Shomaf
}

Received: 17 November 2008/Accepted: 31 July 2009/Published online: 19 August 2009

(C) Springer-Verlag 2009

\begin{abstract}
Intramuscular myxomas of the hand are rare entities. Primarily found in the myocardium, these lesions also affect the bone and soft tissues in other parts of the body. This article describes a case of hypothenar muscles myxoma treated with local surgical excision after frozen section biopsy with tumor-free margins. Radiographic images of the axial and appendicular skeleton were negative for fibrous dysplasia, and endocrine studies were within normal limits. The 8-year follow-up period has been uneventful, with no complications. The patient is currently recurrence free, with normal intrinsic hand function.
\end{abstract}

Keywords Myxoma $\cdot$ Hand $\cdot$ Neoplasm $\cdot$ Hypothenar

\section{Introduction}

Intramuscular myxoma is a relatively uncommon benign myxoid soft tissue tumor, named for their abundance of non-collagenous mucinous stroma, composed of undifferentiated stellate or spindle-shaped cells set in a myxoid stroma, made up of a loose matrix of reticulin, collagen fibers, diminished vascularity, and minimal mitotic figures [1]. It presents a slow growing deeply seated mass confined to the skeletal muscle, with the majority of lesions present in fourth to sixth decade of the life with female predominance $[1,2]$. Intramuscular myxoma usually occurs as an

\section{F. O. Abu Hassan $(\bowtie)$}

The Department of Orthopaedic Surgery,

Jordan University Hospital, Amman, Jordan

e-mail: freih@ju.edu.jo

M. Shomaf

Pathology Department, Jordan University Hospital,

Amman, Jordan isolated lesion, but more often as multiple lesions associated with fibrous dysplasia of the bone (Mazabraud's syndrome), or as a part of the McCune-Albright syndrome (polyostotic fibrous dysplasia, café-au-lait spots and endocrine hyperfunction) [3-5]. The most frequent site of occurrence of the myxoma is within the myocardium [6], skeletal muscles of the lower limbs and the jaw bones, but rarely in upper limbs $[1,7,8]$. The osseous lesions are limited to the jaws, has been reported in the calcaneum [9]. Occurrence of myxoma of the hand region is a rare entity. A case of intramuscular myxoma in the hypothenar muscles muscle treated by marginal excision with long-term follow-up is described. This is the first report of this tumor arising in that muscle.

\section{Case report}

A 35-year-old female patient presented with a 4 months history of a slowly growing swelling in the hypothenar area of the right hand. The patient could not recall a history of trauma to the extremity and had no constitutional symptoms. Her medical history was unremarkable. Physical examination of the right hand revealed a firm, well-circumscribed, mobile, non-tender mass measuring $3 \times 3 \mathrm{~cm}$, in the volar surface of the hypothenar muscles, with normal appearance of the skin overlying the mass, and there was no regional lymphadenopathy. The range of motion of the hand joints was not restricted and there was no neurovascular impairment. The plain anterior posterior radiograph of the hand showed nonspecific soft tissue swelling in the ulnar side of the hand in relation to fifth metacarpal bone with no obvious osseous involvement. Magnetic resonance imaging (MRI) of the right hand showed a well-circumscribed mass, lobulated, measuring approximately $3 \times 3 \mathrm{~cm}$ inside the 
Fig. 1 A transverse coronal T1weighted spin-echo MR image shows a lobular homogeneous low-signal intensity mass in the hypothenar muscles, with a rim of tissue of higher signal intensity on the ulnar side

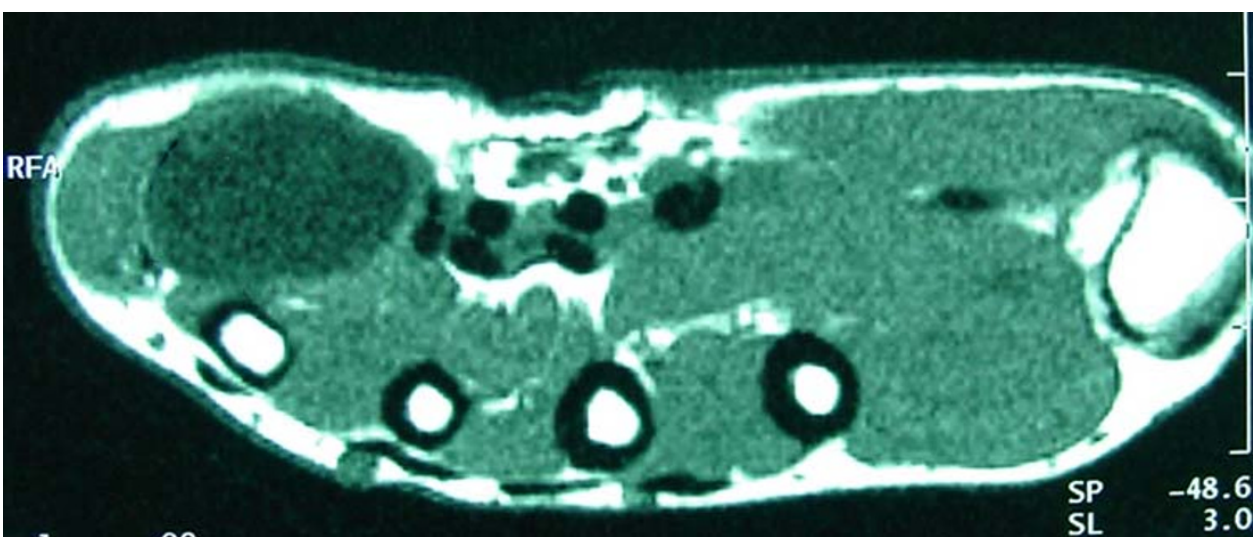

opponens digiti minimi and flexor digiti minimi muscles exhibiting low-signal intensity relative to muscle on the T1weighted images (Fig. 1) and hyperintense to muscle on T2weighted images. The tumor causing lateral displacement of flexors of little finger, with no infiltration of the adjacent structures or bony involvement, but replacing and compressing the hypothenar muscles (Figs. 2, 3). There was no infiltration of ulnar neurovascular bundle.

Laboratory findings were within normal limits. A lazy sshaped incision was made on volar aspect of the hypothenar eminence and the tumor was found within the opponens digiti minimi and flexor digiti minimi muscles, but it did not infiltrate them. An intraoperative frozen section was obtained and the results consistent with a benign myxomatous lesion; the tumor was removed by

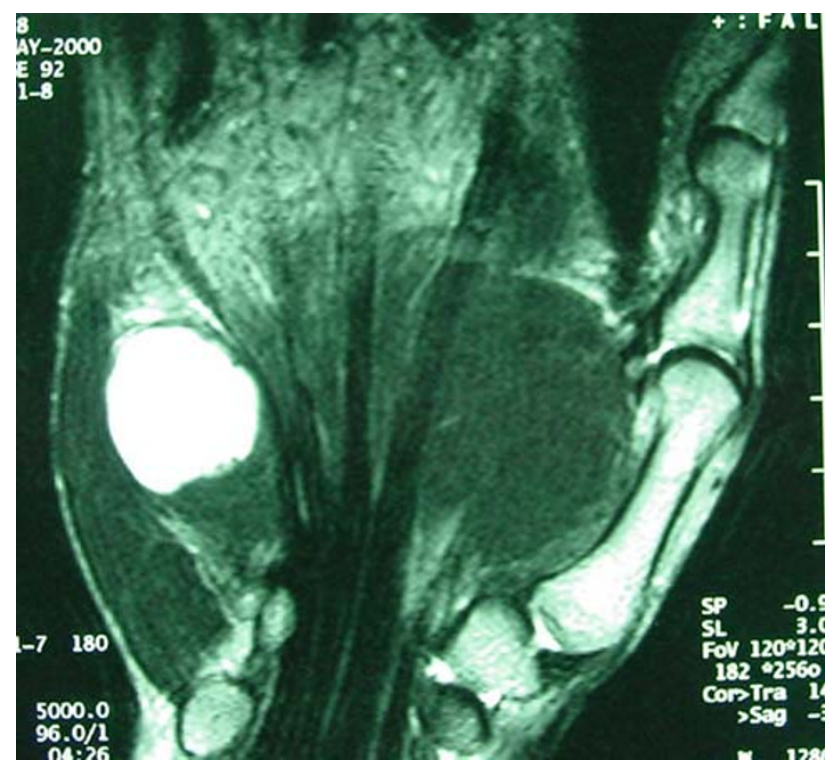

Fig. 2 Magnetic resonance images of the right hand of the patient in T2-weighted sequences showing that the lobulated mass is hyperintense to muscle signals, with displacement of little finger flexors marginal excision. The gross specimen consisted of a well-circumscribed, lobulated, gray brown mass with gelatinous consistency. Histological examination (Fig. 4) showed the lesion composed of uniform, cytological bland spindle, stellate shaped cells with tapering eosinophilic cytoplasm and small nuclei. The cells are separated by abundant myxoid extracellular stroma containing capillarysized blood vessels. In some areas the tumor is surrounded by fibrous capsule. The periphery of the tumor shows infiltration in between muscle fibers (Fig. 5). No nuclear pleomorphism, necrosis, or mitotic activity was evident, but there was no infiltration either in MRI or intraoperatively. Radiographic images of the axial and appendicular

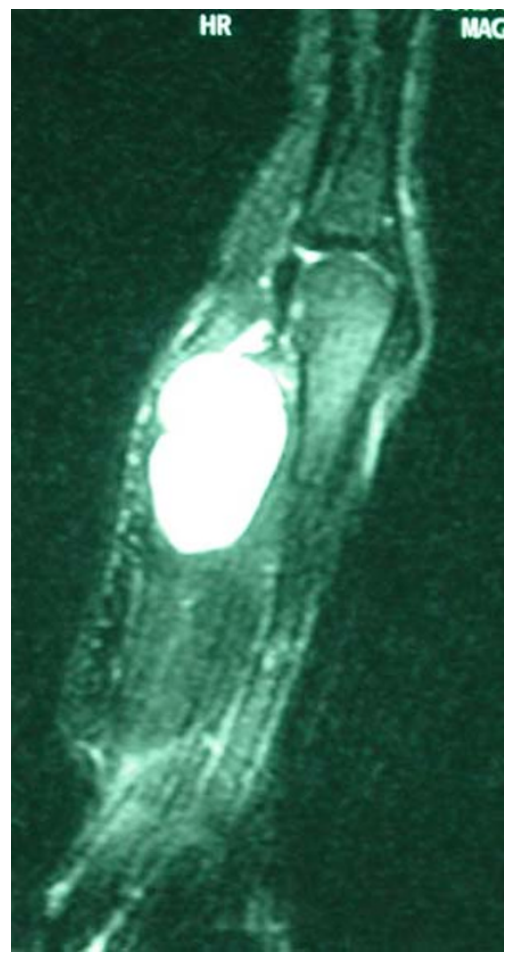

Fig. 3 A sagittal T2-weighted MR image shows a lobulated hyperintense mass in the hypothenar muscles with no bony involvement 


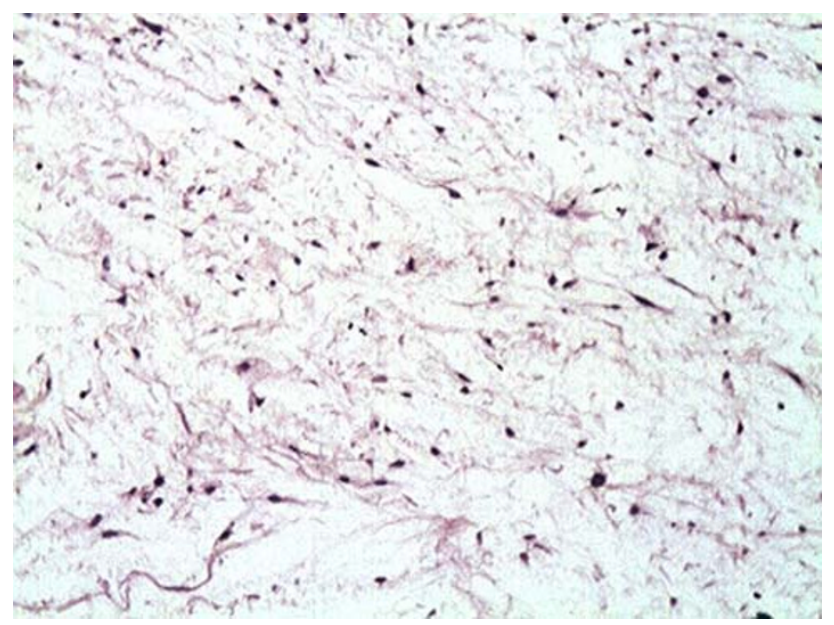

Fig. 4 Bland spindle and stellate cells separated by extracellular myxoid matrix $(\times 400)$

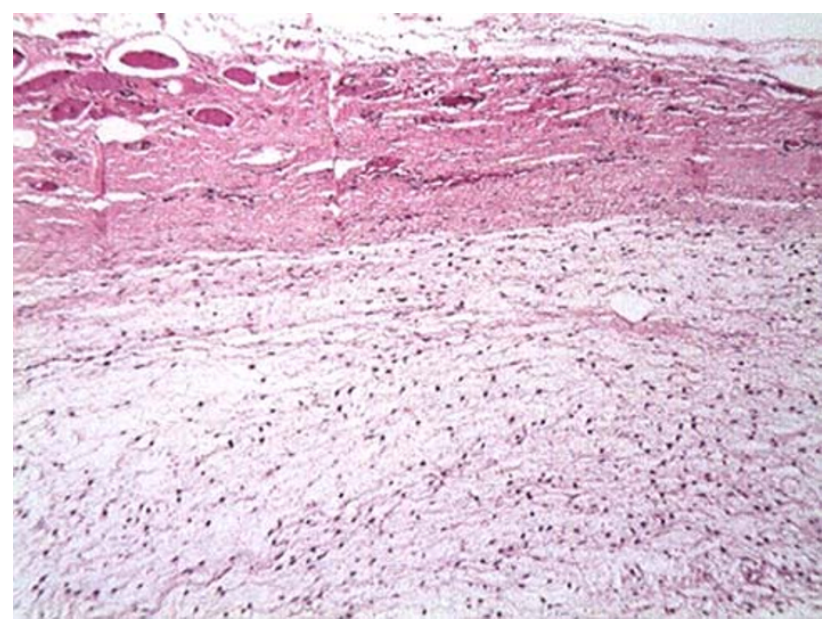

Fig. 5 The tumor infiltrates into the surrounding skeletal muscle separating individual fibers $(\times 100)$

skeleton were negative for fibrous dysplasia, and endocrine studies were within normal limits. Follow-up for 8 years revealed no evidence of recurrence.

\section{Discussion}

The intramuscular myxoma is a benign tumor of the soft tissues of undefined origin. It may originate from fibroblasts which are not sufficiently differentiated and thus not able to synthesize collagen or originate from mesenchymal pluripotent cells $[1,10]$. Soft tissue myxoma of the hand was classified according to site of origin [7], from subcutaneous tissues [7, 11, 12], the palmar fascia and flexor retinaculum [13], and rarely from hand muscles [14]. Usually intramuscular myxomas occur in the skeletal muscles of the thigh and gluteal region $[1,15]$. In the upper limb, two cases of intramuscular myxoma of the deltoid region, seven cases of arm, four cases of the forearm, and one case of intramuscular myxoma of the thenar muscles were described [14, 16-18]. The current case represents the first intramuscular myxoma of the hypothenar muscles. Clinically, intramuscular myxoma presents as a painless, palpable mass and its symptoms are dependent on size and site of the mass $[8,10]$. Plain radiograph may show nonspecific soft tissue mass with no calcification as in our case. The sonographic appearances of intramuscular myxomas appears as well-defined, ovoid masses surrounded by normal muscle, with decreased echogenicity and the presence of small fluid-filled clefts and cystic areas [19].

On computed tomography, intramuscular myxoma is a well-defined homogenous lesion, an appearance similar to that of a cyst or low-density mass within muscles at which demonstrated low attenuation [20]. MR images may show a pseudo capsule, perilesional fat or perilesional edema. Our case did show pseudo capsule separating the tumor from surrounding tissues. Intramuscular myxoma has homogenous low-signal intensity relative to skeletal muscle on T1weighted images and homogenous bright signal intensity on T2-weighted images, sometimes heterogeneous signal intensity due to fibrous septa [20-22].

In our case, magnetic resonance (MR) imaging revealed well-defined, sharply demarcated tumor exhibiting lowsignal intensity relative to muscle on the T1-weighted images and hyperintense to muscle on T2-weighted images. The differential diagnosis of myxoid lesions of the extremities includes benign intramuscular tumor such as myxoid schwannoma and neurofibroma, mesenchymal repair, ganglion cyst, lipoma, hemangioma, hematoma, desmoid tumor, as well as malignant neoplasms such as myxoid liposarcoma, fibrosarcoma, malignant fibrous histiocytoma, rhabdomyosarcoma, synovial sarcoma and extra-skeletal chondrosarcoma $[1,2,10]$. Initial diagnosis can be checked by core needle biopsy, $[15,19]$ or intraoperative frozen section [16]. Our case had preliminary intraoperative diagnosis by histopathological diagnosis by frozen section specimen. Recurrence of intramuscular myxomas is rare and restricted to isolated cases, and more common with associated syndromes $[3,5,11]$.

Meticulous local excision with histological free margins of tumor provides excellent local control [1, 12, 15]. Our case treated by marginal excision and followed for 8 years, there was no impairment of the intrinsic function of the hand and no recurrence. Intramuscular myxoma is a benign nonrecurring tumor and should be remembered when dealing with painless mobile muscular swellings. Although MRI offers a helpful description, a differential diagnosis of intramuscular myxoma from other aggressive tumors can only be made by histological examination. 


\section{References}

1. Allen PW (2000) Myxoma is not a single entity: a review of the concept of myxoma. Ann Diagn Pathol 4:99-123

2. Nielsen GP, O'Connell JX, Rosenberg AE (1998) Intramuscular myxoma: a clinicopathologic study of 51 cases with emphasis on hypercellular and hypervascular variants. Am J Surg Pathol 22:1222-1227

3. Logel RJ (1976) Recurrent intramuscular myxoma associated with Albright's syndrome. J Bone Jt Surg Am 58:565-568

4. Prayson MA, Leeson MC (1993) Soft tissue myxomas and fibrous dysplasia of bone: a case report and review of literature. Clin Orthop 291:222-228

5. Szendroi M, Rahoty P, Antal I, Kiss J (1998) Fibrous dysplasia associated with intramuscular myxoma (Mazabraud's syndrome): a long-term follow-up of three cases. J Cancer Res Clin Oncol 124:401-406

6. Burke AP, Virmani R (1993) Cardiac myxoma: a clinicopathologic study. Am J Clin Pathol 100:671-680

7. Al-Qattan MM (1996) Myxoma of the hand. J Hand Surg Br 21:690-692

8. Charron P, Smith J (2004) Intramuscular myxomas: a clinicopathologic study with emphasis on surgical management. Am Surg 70:1073-1077

9. Abu Hassan FO (2002) Extragnathic fibromyxoma of the calcaneum: report of a case. Foot Ankle Surg 8:59-62

10. Van Roggen JGF, McMenamin ME, Fletcher CDM (2001) Cellular myxoma of soft tissue: a clinicopathological study of 38 cases confirming indolent clinical behaviour. Histopathology 39:287-297
11. Fletcher JW, Watson HK, Weinzweig J (2000) Recurrent myxoma of the hand. J Hand Surg Am 25:772-775

12. Winke BM, Blair WF, Benda JA (1988) Myxomas in the finger tips. Clin Orthop 237:271-273

13. Tolhurst DE (1973) Myxoma of the palm. Hand 5:260-262

14. Al-Qattan MM, El-Shayeb A, Rasool MN (2004) An intramuscular myxoma of the hand. Hand Surg 9:97-99

15. Silver WP, Harrelson JM, Scully SP (2002) Intramuscular myxoma: a clinicopathologic study of 17 patients. Clin Orthop Relat Res 403:191-197

16. Darlis NA, Korompilias AV, Skopelitou AS, Petropoulou KA, Soucacos PN (2005) Soft tissue mass in the proximal forearm of a 17-year-old girl. Clin Orthop Relat Res 437:265-270

17. Ly JQ, Bau JL, Beall DP (2003) Forearm intramuscular myxoma. AJR Am J Roentgenol 181:960

18. Valer A, Carrera L, Ramirez G (1993) Myxoma causing paralysis of the posterior intraosseous nerve. Acta Orthop Belg 59:423-425

19. Liu JC, Chiou HJ, Chen WM, Chou YH, Chen TH et al (2004) Sonographically guided core needle biopsy of soft tissue neoplasms. J Clin Ultrasound 32(6):294-298

20. Murphey MD, McRae GA, Fanburg-Smith JC, Temple HT, Levine AM, Aboulafia AJ (2002) Imaging of soft-tissue myxoma with emphasis on CT and MR and comparison of radiologic and pathologic findings. Radiology 225:215-224

21. Bancroft LW, Kransdorf MJ, Menke DM, O'Connor MI, Foster WC (2002) Intramuscular myxoma: characteristic MR imaging features. AJR Am J Roentgenol 178:1255-1259

22. Luna A, Martinez S, Bossen E (2005) Magnetic resonance imaging of intramuscular myxoma with histological comparison and a review of the literature. Skeletal Radiol 34:19-28 